\title{
Kinetics and thermodynamics of photocatalytic degradation of organic pollutants in petroleum refinery wastewater over nano-TiO 2 supported on Fe-ZSM-5
}

\author{
Zahra Ghasemi $^{\mathrm{a}}$, HabibollahYounesi ${ }^{\mathbf{a}^{*}}$, Ali Akbar Zinatizadeh ${ }^{\mathrm{b}}$ \\ ${ }^{a}$ Department of Environmental Science, Faculty of Natural Resources, Tarbiat Modares \\ University, Noor, Iran \\ ${ }^{b}$ Department of Applied Chemistry, Faculty of Chemistry, Razi University, Kermanshah, Iran
}

\begin{abstract}
The photocatalytic degradation of organic pollutants in a real petroleum refinery wastewater (PRWW) by a heterogeneous photocatalytic process using synthesized nano- $\mathrm{TiO}_{2}$ supported on Fe-ZSM-5 zeolite as photocatalyst irradiated with UV light has been studied. The influence of various operational parameters such as photocatalyst concentration, $\mathrm{pH}$ and temperature was investigated. The degradation rates of the organic pollutants followed mainly a pseudo-first order kinetic model. Results showed that the maximum photodegradation efficiency was achieved at a photocatalyst concentration of $3 \mathrm{~g} \cdot \mathrm{l}^{-1}, \mathrm{pH}$ of 4 and temperature of $45^{\circ} \mathrm{C}$ under UV irradiation time of $120 \mathrm{~min}$. $\mathrm{TiO}_{2}$ loaded with the existence of oxo-iron ions in the framework of zeolite increased photocatalytic degradation of COD. The kinetics of photodegradation reaction was accelerated by an increase in temperature in the range of 15$45^{\circ} \mathrm{C}$. The activation energy for photocatalytic degradation of organic pollutants in PRWW was $18.76 \mathrm{~kJ} \cdot \mathrm{mol}^{-1}$. Thermodynamic parameters of activation were assessed in the photodegradation process. Kinetics computation using transition state theory (TST) showed that the temperature had a significant effect on the rate constants during the photocatalytic
\end{abstract}

\footnotetext{
*Corresponding Author: Email: hunesi@modares.ac.ir, hunesi@yahoo.com Tel: +98(11)44553101-3, Fax: +98(11)44553499
} 
degradation process. Significant photodegradation efficiency of organic pollutants using the synthesized photocatalyst indicates a good potential for this technique as a treatment system for real PRWW.

Keywords: nano- $\mathrm{TiO}_{2} / \mathrm{Fe}-\mathrm{ZSM}-5$, TST, Thermodynamic, kinetic

\section{Introduction}

Petroleum refineries use a large volume of water and consequently generate a significant amount of wastewater. PRWW based on the type of oil being processed as well as the plant configuration and operation procedure contains a high concentration of pollutants namely aliphatic and aromatic petroleum hydrocarbons. The traditional treatment techniques of refinery wastewater consist of two main treatment stages. The first stage is based on the mechanical and physicochemical processes and the second stage is the biological treatment of the pretreated primary effluent in the integrated activated sludge [1].

Photocatalytic degradation process using $\mathrm{TiO}_{2}$ offers some advantages, including no formation of sludge, complete conversion of contaminants to relatively harmless end products, reuse of $\mathrm{TiO}_{2}$ catalyst, and removal of both organic and inorganic pollutants simultaneously. This simultaneous removal is of great importance, particularly, considering a multi-contaminated wastewater such as the PRWW. Some studies have reported the photocatalytic treatment of different real wastewaters such as tannery wastewater [2], municipal wastewater [3] and textile industrial wastewater [4, 5] using $\mathrm{TiO}_{2}$ as photocatalyst. In recent years, development of new complex molecular assemblies as photocatalysts with improved efficiency is an active area of research. The balance between charge separation, ease of interfacial electron transfer and energy-wasting charge recombination determine the efficiency of the photocatalyst [6]. The particular focus of most of the studies has been on 
nanosized $\mathrm{TiO}_{2}$ particles, which increase photocatalytic activity as compared to larger size particles [7]. ZSM-5 and transition metal modified zeolites are considered photocatalytically active for organic compound degradation under UV irradiation [8]. Zeolite can be converted to a photocatalyst by incorporation of heteroatoms such as iron ( $\mathrm{Fe})$ [9]. Isolated $\mathrm{Fe}$ in the zeolite framework results in the photocatalytic activity of Fe-ZSM-5.

In this study, the kinetic and equilibrium data were modeled using Langmuir-Hinshelwood (L-H) model and the temperature dependence of rate constant was described by the Arrhenius and transition state models. The effect of temperature was determined by the kinetic studies and the thermodynamic parameters (standard enthalpy, entropy and Gibbs free energy change of activation) were also calculated. Results are presented for the kinetics of degradation of organic pollutants under different photocatalyst concentrations, reaction $\mathrm{pH}$ and reaction temperatures.

\section{Materials and methods}

\subsection{Analytical procedures and photoreactor operation}

The PRWW was collected from the point that the wastewater is just leaving the oil and grease removal unit and just at the inlet to the dissolved air flotation for coagulation and flocculation treatment unit in Bandar Abbas refinery plant, southern Iran. The wastewater was stored at $4^{\circ} \mathrm{C}$. The physicochemical parameters of wastewater, including the chemical oxygen demand (COD), biological oxygen demand (BOD), total suspended solids and turbidity were determined according to standard methods for the examination of water and wastewater [10] which are summarized in Table 1.

Table 1.

The experiments were conducted in a photoreactor. Irradiation was carried out using a mercury UV lamp (Philips, 8W BLB T5, Netherlands) with $302.5 \mathrm{~mm}$ body length and 16 
mm diameter. The wavelength range of the lamp was 280-400 nm (within the range of UVA and UVB) with the highest irradiation peak of $365 \mathrm{~nm}$. The UV lamp was placed inside a quartz tube and vertically located at the center of the photoreactor of $1000 \mathrm{ml}$ capacity. The photoreactor vessel was equipped with a water jacket conducted to an external circulating flow of a water bath which provided an adjustable temperature. The photoreactor was placed on a magnetic stirrer for a good mixing of the wastewater surrounding the lamp inside the reactor to achieve an average equal UV exposure. Dissolved oxygen supply for photocatalysis in reaction system was provided by an air pump located below the reactor equipped with a fine bubble diffuser with a constant airflow rate of $2.01 \cdot \mathrm{min}^{-1}$.

Wastewater $\mathrm{pH}$ was adjusted with 1.0 M NaOH (Merck) and 1.0 $\mathrm{M} \mathrm{HCl}$ (Merck). The $\mathrm{pH}$ of wastewater was measured by a pH meter (Cyber Scan, Singapore). Prior to irradiation, a 500 $\mathrm{ml}$ of PRWW and the appropriate amount of photocatalyst were transferred into the reactor. The synthesis procedure and characterization of photocatalyst were provided in supplementary materials (S2-S6, Fig. S1-S8 and Table S1). Afterwards, the suspension in the reactor was constantly aerated and magnetically stirred in the dark condition for $120 \mathrm{~min}$ to ensure the adsorption equilibrium. After adjustment of temperature, the reactor set up was covered with a wooden box to prevent UV radiation leakage and then, the UV irradiation was begun. During the process, samples $(5 \mathrm{ml})$ were taken before UV exposure and after 30, 60, 90 and $120 \mathrm{~min}$ UV exposure to evaluate COD removal efficiency and to follow the mineralization process. Thereafter, the samples were allowed to settle for a period of 60 min for separation of the photocatalyst particles and then the COD of the samples were measured by subtracting initial values from final values and divided by initial value and multiplying by 100 .

The experiments were repeated three times and the results were averaged. The standard deviations were found to be less than $5 \%$. 


\subsection{Parameter effects on the photocatalytic degradation of COD}

The effects of the $\mathrm{TiO}_{2} / \mathrm{Fe}-\mathrm{ZSM}-5$ concentration e $\left(1,2,3\right.$ and $\left.4 \mathrm{~g} \cdot \mathrm{l}^{-1}\right)$ on photocatalytic COD removal in PRWW were studied. The $\mathrm{pH}$ of the working wastewater was adjusted to 4 by adding $0.1 \mathrm{M} \mathrm{HCl}$. The experiments were carried out at $45^{\circ} \mathrm{C}$ for $120 \mathrm{~min}$. Fresh wastewater was used for each experiment.

The effect of the different initial wastewater $\mathrm{pH}$ on the photocatalytic degradation was investigated by mixing $0.5 \mathrm{~g}$ of $\mathrm{TiO}_{2} / \mathrm{Fe}-\mathrm{ZSM}-5$ photocatalyst concentration $\left(1 \mathrm{~g} .1^{-1}\right)$ in 500 $\mathrm{ml}$ of wastewater at $45^{\circ} \mathrm{C}$ for $120 \mathrm{~min}$. The $\mathrm{pH}$ was adjusted to values 4,6 and 8 using $0.1 \mathrm{M}$ $\mathrm{HCl}$ and $0.1 \mathrm{M} \mathrm{NaOH}$ solution. After settlement of the photocatalyst, the COD of the treated wastewater was measured.

The effects of temperature $\left(15,35\right.$ and $\left.45^{\circ} \mathrm{C}\right)$ on photocatalytic treatment were investigated with $1 \mathrm{~g}$ of $\mathrm{TiO}_{2} / \mathrm{Fe}-\mathrm{ZSM}-5$ photocatalyst concentration $\left(2 \mathrm{~g}^{\cdot-1}\right)$ in $500 \mathrm{ml}$ of wastewater at pH 6 for $120 \mathrm{~min}$. The temperature was maintained by a water jacket conducted to an external circulating flow of a water bath (at required temperature)

\subsection{Kinetics of photodegradation of $P R W W$}

For surface photocatalytic degradation reaction, we use the L-H model to describe the initial rates of photocatalytic removal of COD.

$r_{o}=-\frac{d C}{d t}=\frac{k_{r} K C}{1+K C}$

where, $r_{\mathrm{o}}$ is the initial rate of the disappearance of the COD concentration, $C$, the equilibrium bulk-solute concentration and $t$ the reaction time. $K$ represents the equilibrium constant for adsorption of COD on to illuminated photocatalyst and $k_{\mathrm{r}}$ reflects the limiting rate constant of the reaction at maximum coverage under the given experimental conditions. In the case of highly diluted solution and the term $K C$ becomes less than 1 , when the denominator of Eq. (2) 
neglected and the rate data can be modeled by the apparent first-order kinetics as in the following equation:

$r=-\frac{d C}{d t}=k_{r} K C=k_{a p p} C$

where $C_{\mathrm{A}}$ is the $\mathrm{COD}$ concentration at time $t$, and $k_{\text {app }}$ the apparent first-order rate constant. Integrating Eq. (3) and using boundary condition $C=C_{\mathrm{o}}$ at $\mathrm{t}=0$ gives:

$\ln \left(\frac{C_{t}}{C_{o}}\right)=-k_{a p p} t$

where, $C_{\mathrm{o}}$ is the COD concentration at the initial time.

\section{Result and discussion}

\subsection{Photodegradation of $P R W W$}

In preliminary experiments, in order to examine the effects of UV irradiation on photodegradation of COD and adsorption of pollutants by photocatalyst, some experiments were conducted under three different conditions, i.e., in the absence of photocatalyst and under the UV light, in the presence of photocatalyst and in the absence of UV light (dark condition), and in the presence of photocatalyst and under UV light. A typical plot of COD removal against time under the above mentioned three conditions is presented in Fig. 1, at a photocatalyst concentration of $2.0 \mathrm{~g} \cdot \mathrm{l}^{-1}, \mathrm{pH}$ of 6.0 , temperature of $35^{\circ} \mathrm{C}$ and $\mathrm{UV}$ exposure time of $120 \mathrm{~min}$.

\section{Figure 1}

Experimental data revealed about $66 \%$ of COD removal in the presence of photocatalyst and UV light, while very low COD removal efficiency of less than $4 \%$ was obtained in the presence of photocatalyst and under the absence of light after $120 \mathrm{~min}$, hence, the COD removal under the absence of light was very slow. The reason of low removal efficiency under the absence of light may be due to either very low adsorption of organic pollutants by the photocatalyst particles, or the volatility of a part of light hydrocarbons due to increased 
temperature of the photoreactor or the airflow. Similarly, in the absence of photocatalyst, when solutions were irradiated by UV light, the COD removal of about $20.8 \%$ was achieved in the absence of photocatalyst. The results clearly indicate that photodegradation process plays a more important role than adsorption process in PRWW treatment using $\mathrm{TiO}_{2} / \mathrm{Fe}-\mathrm{ZSM}$ 5 as a photocatalyst. From Fig. 1, it is obvious that the photocatalytic removal of COD increased with UV exposure time of up to $30 \mathrm{~min}$ and did not change significantly thereafter. This can possibly be explained by the fact that some organic compounds are more sensitive to oxidation than others, while some others are partially oxidized intermediate compounds. However, it is worth noting that very little is known about the formation of the byproducts from organic materials in the effluent water. All these results suggested that the presence of both UV light and photocatalyst are needed for effective treatment of wastewater. The hydroxyl radicals $(\bullet \mathrm{OH})$ with a high oxidation potential of $+2.8 \mathrm{~V}[11]$ are the primary oxidants employed in this organic pollutants degradation process. Under irradiation with energy equal to or greater than the band gap of photocatalyst, a valence band electron $\left(\mathrm{e}^{-}\right)$is promoted to the conduction band, leaving behind a positive hole $\left(\mathrm{h}^{+}\right)$in the valence band [6]. The valence band hole and the conduction band electron are powerful oxidant and reduction agents, respectively. These holes can oxidize water and hydroxide ions to generate hydroxyl radicals; and the electrons in the conduction band can reduce the molecular oxygen to a super oxide anion $\left(\mathrm{O}_{2}{ }^{-}\right)$. The photon-generated electrons $\left(\mathrm{e}_{\mathrm{cb}}{ }^{-}\right)$, holes $\left(\mathrm{h}_{\mathrm{vb}}{ }^{+}\right)$and hydroxyl radicals $(\bullet \mathrm{OH})$ can degrade organic pollutant to intermediates, and then the intermediates are more degraded to final products $[12,13,14,6]$.

\subsubsection{Effect of photocatalyst concentration}

The influence of $\mathrm{TiO}_{2} / \mathrm{Fe}-\mathrm{ZSM}-5$ concentration on the rate of COD removal was studied (Fig.

2a). The apparent first-order rate constant is given for $\mathrm{TiO}_{2} / \mathrm{Fe}-\mathrm{ZSM}-5$ concentration of $1,2,3$ 
and $4 \mathrm{~g} / \mathrm{l}$ (Fig. 2b). The plot of $\ln \left(C_{\mathrm{t}} / C_{\mathrm{o}}\right)$ versus reaction time gives a good linear relationship (with $R^{2}>0.99$ ), which is evidence of the good agreement of fitting the reaction data in firstorder reaction and the first-order rate can be estimated by the apparent reaction rate constant attained from the slope of the linear regression of the results. Considering the concentration of the photocatalyst and their rate constants in the PRWW degradation reaction (Fig. 2b), it can be explained that the dose of the photocatalyst positively correlates with their photocatalytic performance, indicating that organic materials degradation of PRWW is dependant on the number of available photodegradation holes. However, the results also indicate that the surface area is not the only major factor affecting the photocatalytic activity. The photocatalytic degradation of organic pollutants in many cases showed this behavior $[15,16$, 17].

The maximum removal efficiency was obtained at a photocatalyst concentration of $3 \mathrm{~g} \cdot \mathrm{l}^{-1}$. It has been found that the rate of photodegradation increases with increasing $\mathrm{TiO}_{2} / \mathrm{Fe}-\mathrm{ZSM}-5$ concentration from 1 to $3 \mathrm{~g}^{-1}{ }^{-1}$; thereafter, further increase in photocatalyst loading decreased the rate of COD removal up to $4 \mathrm{~g} \cdot \mathrm{l}^{-1}$. In addition, it is obvious that $k_{\text {app }}$ increased with an increase in photocatalyst concentration up to a certain limit $\left(3 \mathrm{~g} \cdot \mathrm{l}^{-1}\right)$ after which, a decrease in $k_{\text {app }}$ was observed. This is in agreement with earlier reports $[15,16,17]$.

The observed enhancement in the photodegradation in the range of $1-3 \mathrm{~g} \cdot \mathrm{l}^{-1}$ concentration is probably due to an increased number of active sites on the photocatalyst surface available for reaction. Further increasing of $\mathrm{TiO}_{2}$ loading beyond the optimum concentration may cause the tendency toward agglomeration (particle-particle interaction) of free catalyst, which in turn reduce the available surface area and active sites for light absorption and consequently would reduce the photocatalytic degradation efficiency [18]. On the other hand, with the increase of catalyst concentration beyond the optimum concentration, the light transmission through the solution will compromise due to the increase of opacity. It causes a decrease in UV light 
penetration as a result of the increased scattering effect [19], so that the photocatalytic degradation rate would decrease. Another possible reason is that the light has been absorbed almost totally by photocatalyst particles at the optimum concentration [18] and so, the maximum limit of photon absorption is reached within the photoreactor. Many researchers have reported that organic removal efficiency decreases when the catalyst concentration increases beyond a certain limit. These results are consistent with those reported in the literature for photocatalytic degradation of different organic materials [1].

Figure 2

\subsubsection{Effect of $p H$}

A multi-contaminated wastewater such as PRWW contains different organic pollutants which can attain a positive or negative charge, as well as the neutral form at a specific $\mathrm{pH}$ value. In addition, $\mathrm{pH}$ value of the wastewater is an important effective parameter on the surface charge properties of the photocatalyst, the adsorption behavior of pollutants and consequently on the rate of photocatalytic degradation of organic pollutants taking place on the photocatalyst particulate surface [20]. Therefore, it is important to study the role of $\mathrm{pH}$ on photocatalytic degradation and to determine the optimum $\mathrm{pH}$ for PRWW treatment [1]. Fig. 3a shows the COD removal efficiency as a function of $\mathrm{pH}$ under using $1 \mathrm{~g} \cdot \mathrm{l}^{-1}$ photocatalyst concentration at a temperature of $45^{\circ} \mathrm{C}$ for $120 \mathrm{~min}$. The apparent first-order rate constant for the reaction of $\mathrm{TiO}_{2} / \mathrm{Fe}-\mathrm{ZSM}-5$ with PRWW decreased nonlinearly with increasing pH (Fig. 3b). In the present study, the maximum photodegradation rate was achieved at $\mathrm{pH} 4$ and the process of COD removal was favored by the protonated surface of photocatalyst. The maximum photodegradation efficiency of $67.05 \%$ was observed at $\mathrm{pH} 4$. However, a COD removal efficiency of about $63 \%$ was occurred at $\mathrm{pH} 8.0$. 
The effect of $\mathrm{pH}$ on the photocatalytic reaction can be explained on the basis of the zero point charge (pzc) of $\mathrm{TiO}_{2} / \mathrm{Fe}-\mathrm{ZSM}-5$ photocatalyst and the adsorption of the pollutants on the photocatalyst in different $\mathrm{pH}$ values [21]. The isoelectric point (IEP) point is the $\mathrm{pH}$ at which the zeta potential is zero. The IEP of $\mathrm{TiO}_{2} / \mathrm{Fe}-\mathrm{ZSM}-5$ photocatalyst depends on the acid-base properties of surface hydroxyl groups. The pzc of synthesized photocatalyst was at $\mathrm{pH} \sim 5.2$ (the dedails are given in supplementary S7). It is to be believed that the surface of photocatalyst is positively charged under acidic condition $(\mathrm{pH}<5.2)$ by the adsorbed $\mathrm{H}^{+}$ions on the semiconductor surface, whereas, it is negatively charged under alkaline conditions $(\mathrm{pH}>5.2)$ by the adsorbed $\mathrm{OH}^{-}$ions on the semiconductor surface as shown in the following reactions:

photocatalyst $-\mathrm{OH}+\mathrm{OH}^{-} \leftrightarrow$ photocatalyst $-\mathrm{O}^{-}+\mathrm{H}_{2} \mathrm{O} \quad$ at $\mathrm{pH}>$ pzc

The anionic or cationic form of the organic compound affects the photodegradation efficiency. This efficiency is enhanced or inhibited by the electrostatic attraction or repulsion, respectively, between the photocatalyst's surface and the organic molecule [20]. Increase of photo degradation rate at $\mathrm{pH} 8$ rather than $\mathrm{pH} 6$ shows that a part of organic compound degradation was favored by the negatively charged photocatalyst. At $\mathrm{pH}$ value of 8 the surface of photocatalyst acquires negative charges and thus has the ability to attract the positively charged organic compounds on its surface, thereby, increasing the degradation rate at $\mathrm{pH} 8$ rather than $\mathrm{pH} 6$.

Under acidic conditions $(\mathrm{pH}<5.2)$, the surface of photocatalyst becomes positively charged due to the surface species (photocatalyst- $\mathrm{OH}^{2+}$ ) and would interact strongly with negatively charged organic compounds [22].

photocatalyst $-\mathrm{OH}+\mathrm{H}^{+} \leftrightarrow$ photocatalyst $-\mathrm{OH}_{2}^{+} \quad$ at $\mathrm{pH}<\mathrm{pzc}$

Our results demonstrated that the rate of organic compound photodegradation would be accelerated under acidic and alkaline conditions rather than $\mathrm{pH}_{\mathrm{pzc}}$ of photocatalyst. Therefore, 
the electrical charge density on the surface of photocatalyst is zero at the $\mathrm{pH}$ value of 5.2. Rate constant $k$ was determined from the first-order plots. The rate of organic compound adsorption on the photocatalyst surface would be accelerated at a $\mathrm{pH}$ value of more or less than $\mathrm{pH}_{\mathrm{pzc}}$ of 5.2.

These results are in line with findings of other researchers reporting photocatalytic degradation of organic materials under different $\mathrm{pH}$ values. The rate of photodecolourization of quinolone yellow dye increased when the $\mathrm{pH}$ rose, exhibiting maximum efficiency (97\%) at $\mathrm{pH} 11.5$ [23]. The maximum removal of organic pollutants of pretreated refinery wastewater of above $90 \%$ was obtained at $\mathrm{pH}$ value of 3 , catalyst concentration of $100 \mathrm{mg} \cdot \mathrm{l}^{-1}$, temperature of $45^{\circ} \mathrm{C}$ and $4 \mathrm{~h} \mathrm{UV}$ irradiation time, using commercial $\mathrm{TiO}_{2}$ [24].

Figure 3

\subsubsection{Effect of temperature}

The effect of temperature on the COD removal rate was significant (Fig. 4a). The results showed that the COD removal rate increased as the temperature rose. The photocatalytic activity of $\mathrm{TiO}_{2} / \mathrm{Fe}-\mathrm{ZSM}-5$ was tested at $1 \mathrm{~g} \cdot \mathrm{l}^{-1}$ photocatalyst concentration and $\mathrm{pH}$ under varying temperatures from 15 to $45^{\circ} \mathrm{C}$. The maximum removal efficiency was achieved at $\underline{\mathrm{a}}$ temperature of $45^{\circ} \mathrm{C}$. The apparent first-order rate constant for the reaction of $\mathrm{TiO}_{2} / \mathrm{Fe}-\mathrm{ZSM}-5$ with PRWW increased linearly with increasing temperature (Fig. 4b), which further confirms that the COD decomposition is a temperature-driven reaction. The increase in temperature from 15 to $45^{\circ} \mathrm{C}$ resulted in an 36 and $26 \%$ increase in the rate constant for $\mathrm{TiO}_{2} / \mathrm{Fe}-\mathrm{ZSM}-5$ photocatalyst, respectively. However, the rate constant was shown to decrease by about $18 \%$ when the reaction temperature increased up to $55^{\circ} \mathrm{C}$. The decrease in temperature favors adsorption of the reactant, which is a spontaneous exothermic phenomenon, but favors the desorption of the final products on the surface of photocatalyst, of which there tends to be the 
rate-limiting step, because it is slower than the decomposition and adsorption of the reactants. By contrast, when the temperature increases, approaching to the boiling point of water, the exothermic adsorption of reactant becomes disfavored and tends to be the rate-limit step. In addition, the final by-products are toxic because they are not completely mineralized to $\mathrm{CO}_{2}$ and dissolved oxygen concentration in the water decreases when the photocatalytic degradation takes place at a high temperature. Therefore, the effect of temperature investigated at optimum $\mathrm{pH}$ of $4, \mathrm{TiO}_{2} / \mathrm{Fe}-\mathrm{ZSM}-5$ concentration of $3 \mathrm{~g} \cdot \mathrm{l}^{-1}$ and $45^{\circ} \mathrm{C}$ was considered to be the optimal operating temperature.

Figure 4

The Arrhenius equation (Eq. 7) was used to calculate the activation energy of reaction [25].

$k_{a p p}=A e^{-\frac{E a}{R T}}$

where, $k_{\text {app }}$ is the apparent reaction rate constant $\left(\min ^{-1}\right), A$ the Arrhenius factor, $E_{\mathrm{a}}$ the activation energy (J) $R$ the ideal gas constant which is equal to $8.314 \mathrm{~J} \mathrm{~K}^{-1} \mathrm{~mol}^{-1}$ and $T$ the temperature (K). The logarithmic form of Eq. 7 can be written as:

$$
\ln k_{a p p}=\ln A-\frac{E_{a}}{R T}
$$

The $E_{a}$ of reaction was calculated from the Arrhenius plot of $\ln k$ against the reciprocal absolute temperature (Eq. 7), using the estimated value of the slope of the straight line. Fig. 5fa shows that the Arrhenius plot of $\ln k$ against $1 / \mathrm{T}$ is made using the rate constants from 15 to $45^{\circ} \mathrm{C}$. The calculated $E_{a} 18.77 \mathrm{~kJ} \mathrm{~mol}^{-1}$ obtained for the photodegradation of organic pollutants in PRWW by $\mathrm{TiO}_{2} / \mathrm{Fe}-\mathrm{ZSM}-5$ is slightly less than the reported activation energy on hydroxyl radical degradation for PRWW treatment using $\mathrm{TiO}_{2}$ nanoparticles [26]. According to the collision theory of reaction kinetics, the constant the Arrhenius factor (A) is substituted by the factors $z p$ and the apparent rate constant for a reaction is given by:

$$
k_{a p p}=z f p
$$


where, $z$ the collision frequency represents the number of collisions per time, $f$ the fraction of effective collisions represents the fraction of collisions with sufficient energy $\left(E_{a}\right)$ to react and $p$ the steric factor represents the fraction of collisions with the proper orientation to react (independent of absolute temperature). The $f$ with sufficient $E_{a}$ is temperature dependent and $k_{\text {app }}$ can be written by the following expression:

$k_{a p p}=z p e^{-\frac{E_{a}}{R T}}$

The photocatalytic degradation of organic pollutants (OPs) can also be described by the TST, assuming the existence of a stable activated complex $\mathrm{X}^{\ddagger}$ in equilibrium with the reactant:

$\mathrm{OPS} \stackrel{K^{\ddagger}}{\leftrightarrow} X^{\neq} \stackrel{v}{\rightarrow} \mathrm{CO}_{2}+\mathrm{H}_{2} \mathrm{O}$

where, $\mathrm{X}^{\ddagger}$ is the concentration of an activated complex of TST at the top of the barrier and COD the reactant and is always in equilibrium with $\mathrm{X}^{\ddagger}$. The equilibrium constant may be written as:

$K^{\ddagger}=\frac{\left[X^{\ddagger}\right]}{[C O D]}$

The rate for the photocatalytic degradation may be expressed as follows:

$r=-\frac{d C}{d t}=v\left[X^{\ddagger}\right]$

where, $v$ is the frequency of crossing the activation energy barrier. Substituting $X^{\star}$ from Eq.

(12) into Eq. (13) gives:

$r=-\frac{d C}{d t}=v K^{\ddagger}[C O D]$

Thus, the apparent rate constant of photocatalytic degradation can be expressed as follows:

$k_{a p p}=v K^{\ddagger}$

According to TST, Eq. (15) shows that the apparent rate of reaction is the product of two magnitudes, the probability of forming the activated complex and the effective rate of crossing the barrier energy by the activated complexes (frequency vibration, $v$ ). Statistical mechanics provides that the value of universal $v$ is dependent on the temperature and is 
independent of the nature of the reactants and type of reaction, is equal to $K_{\mathrm{B}} T / h$ where $K_{\mathrm{B}}$ is the Boltzmann's constant $\left(1.3805 \times 10^{-23} \mathrm{~J} \mathrm{~K}^{-1}\right)$ and $h$ the Planck's constant $\left(6.6261 \times 10^{-34} \mathrm{~J}\right.$ s). To reveal the thermodynamics of the theory, $K^{\ddagger}$ must be expressed in terms of standard Gibbs free energy change of activation $\left(\Delta^{\ddagger} G^{o}\right)$, which can be expressed as:

$K^{\ddagger}=e^{-\frac{\Delta^{\ddagger} G^{o}}{R T}}$

Therefore, the temperature dependent on the photocatalytic apparent rate constant is now expressed by the following equation:

$k_{\text {app }}=\frac{K_{B} T}{h} e^{-\frac{\Delta^{\ddagger} G^{O}}{R T}}$

In the thermodynamic properties of TST, the change in the standard enthalpy $\left(\Delta^{\ddagger} H^{o}\right)$ and entropy of activation $\left(\Delta^{\ddagger} S^{o}\right.$ ) are brought together by the change in the standard Gibbs free energy of activation equation:

$\Delta^{\ddagger} \mathrm{G}^{\mathrm{o}}=\Delta^{\ddagger} \mathrm{H}^{\mathrm{o}}-\mathrm{T} \Delta^{\ddagger} \mathrm{S}^{\mathrm{o}}$

Substituting $\Delta^{\ddagger} G^{o}$ from Eq. (18) into Eq. (17) gives:

$k_{a p p}=\left(\frac{K_{B} T}{h}\right) e^{\frac{\Delta^{\ddagger} S^{o}}{R}} \times e^{-\frac{\Delta^{\ddagger} H^{o}}{R T}}$

Eq. (19) can be expressed in the linear form of the Henry Eyring's formulation as:

$\ln \left(\frac{k_{a p p}}{T}\right)=\ln \left(\frac{K_{B}}{h}\right)+\frac{\Delta^{\ddagger} S^{o}}{R}-\frac{\Delta^{\ddagger} H^{o}}{R T}$

The $\Delta^{\ddagger} H^{o}$ and $\Delta^{\ddagger} S^{o}$ of photocatalytic degradation of OPs was calculated from the plot of $\ln \left(k_{\mathrm{app}} / \mathrm{T}\right)$ against the reciprocal absolute temperature (Eq. 19), using the estimated value of the slope of the straight line, respectively. A linear plot of $\ln \left(k_{\mathrm{app}} / T\right)$ against reciprocal $\mathrm{T}$ yields a straight line (Fig. 5b) from which the change in the standard enthalpy $\left(\Delta^{\ddagger} H^{o}\right)$ and entropy of activation $\left(\Delta^{\circ} S^{\circ}\right.$ can be obtained and are given in Table 2. The standard Gibbs free energy change of activation $\left(\Delta^{\ddagger} G^{o}\right)$ was calculated using Eq. (18).

Figure 5

Table 2 
If Arrhenius (Eq. 7) and collision (Eq. 10) theories are compared to TST (Eq. 19), then:

$A=z p=\left(\frac{K_{B} T}{h}\right) e^{\frac{\Delta^{\ddagger} S^{o}}{R}}$

By differentiating Eq. (7) and Eq. (19) with respect to temperature, leading to the final equation:

$\Delta^{\ddagger} \mathrm{H}^{\mathrm{o}}=\mathrm{E}_{\mathrm{a}}-\mathrm{RT}$

The positive values of $\Delta^{\ddagger} H^{\mathrm{o}}$ and the increasing value of $k_{\text {app }}$ with increasing temperature indicate that the photodegradation of PRWW using the $\mathrm{TiO}_{2} / \mathrm{Fe}-\mathrm{ZSM}-5$ is an endothermic process [27]. The endothermic nature of photocatalytic degradation is probably due to the electrostatic interaction between the high hydrophobic nature of photocatalyst and organic pollutants. High hydrophobic surface property of Fe-ZSM-5 was derived from the $\mathrm{SiO}_{2} / \mathrm{Fe}_{2} \mathrm{O}_{3}$ ratio of the zeolite framework components. Hydrophobic surface property of Fe-ZSM-5 and synthesized photocatalyst cause a smooth adsorption of organic pollutants into a photocatalyst framework to achieve efficient photocatalytic degradation. It was also observed that with an increase in experimental temperature, the positive values of standard Gibbs free energy change of activation $\left(\Delta^{\ddagger} G^{\circ}>0\right)$ increased. The large positive $\Delta^{\ddagger} G^{\circ}$ at the higher temperature indicated no spontaneous processes and weak adsorption of organic pollutants on $\mathrm{TiO}_{2} / \mathrm{Fe}-$ ZSM-5. An increase in temperature facilitates the photocatalytic reactions to compete more efficiently with electron-hole pair recombination [23]. In addition, an increase in temperature would facilitate the electron transfers of $\mathrm{TiO}_{2}$ in the valence band to higher energy levels [28]. The maximum $k_{\text {app }}$ at temperature of $45^{\circ} \mathrm{C}$ confirmed the above explanation.

\subsection{Studies upon photocatalyst recycling}

A cost-effective solution of the photocatalytic process of organic pollutant of PRWW degradation efficiency was implemented for a number of working cycles in order to maintain its photoactivity. The possibility to reuse the photocatalyst $\mathrm{TiO}_{2} / \mathrm{Fe}-\mathrm{ZSM}-5$, the experiments 
were performed by immersing in PRWW and irradiated by UV light for $60 \mathrm{~min}$. When the organic materials were degraded, $\mathrm{TiO}_{2} / \mathrm{Fe}-\mathrm{ZSM}-5$ photocatalysts were reused for further PRWW immersion COD removal measurements. The results showed that Fe-ZSM-5 particles coated with $\mathrm{TiO}_{2}$ layers by 2 , and 3 cycles could decompose organic materials of PRWW by slight decreases in the COD removal of 1.15 and 3.05, respectively. After the third experimental cycle run, the photocatalyst was recovered and calcined at $600^{\circ} \mathrm{C}$ for $4 \mathrm{~h}$ and then employed again in the reusability tests for 4 and 5 cycles. The loss in percentage of photocatalytic decomposition was about 1.48 and $1.52 \%$ after the 4 and 5 cycles, respectively. As a result, the calcination process seems to be necessary for regenerating the activity of the reused photocatalyst, due to blocking of active sites by organic materials of wastewater and thus decreasing the photocatalytic activity of $\mathrm{TiO}_{2} / \mathrm{Fe}-\mathrm{ZSM}-5$. The photocatalytic efficiency of more than $83 \%$ was obtained even after five successive cycles, showing its photoactivity. Our results have demonstrated that by introducing Fe-ZSM-5 with a coated layer of $\mathrm{TiO}_{2}$, the highly efficient photocatalyst can be designed in a way that would be stable and reusable after several treatment cycles without losing its photocatalytic activity.

\subsection{Comparison of photocatalytic activity of $\mathrm{TiO}_{2} / \mathrm{Fe}-\mathrm{ZSM}-5$ and commercial nanosized $\mathrm{TiO}_{2}$}

Under optimum conditions, the comparative study of the photocatalytic activity of $\mathrm{TiO}_{2} / \mathrm{Fe}$ ZSM-5 and a simple mix of zeolite and commercial nanosized $\mathrm{TiO}_{2}$ Degussa (P25, SigmaAldrich, USA) on the degradation of PRWW was also carried out using a photocatalyst

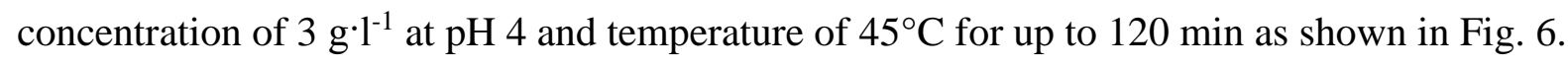
The surface adsorption of the photocatalyst samples was investigated by determining the change of the percentage COD removal after dispersing the samples into the PRWW in the dark for a 120 min period prior to the degradation experiment. The results showed that $\mathrm{Fe}$ ZSM-5 coated with $\mathrm{TiO}_{2}$ could degrade more than $83 \%$ of the COD of PRWW absorbed on 
them through UV irradiation of 120 min, while a simple mix of zeolite and commercial nanosized $\mathrm{TiO}_{2}$ Degussa (P25) could achieve a decomposition of about $64 \%$ within 120 min, as shown in the inset of Fig. 6. However, we observed that the $\mathrm{TiO}_{2} / \mathrm{Fe}-\mathrm{ZSM}-5$ and a simple mix of zeolite and commercial nanosized $\mathrm{TiO}_{2}$ Degussa (P25) showed very low percentage adsorption of organic pollutants at about 1 and $2 \%$, respectively, in the dark condition. Our results demonstrated that coating $\mathrm{TiO}_{2}$ nanoparticles supported on Fe-ZSM-5 zeolite and the existence of oxo-iron ions in the framework of zeolite are important and can significantly increase the photocatalytic activity for COD degradation of PRWW sample. For Fe-ZSM-5, each $\mathrm{Fe}$ forms a disordered oxygen with $\mathrm{Fe}-\mathrm{O}$ bonds in the $\mathrm{FeO}_{4}$ tetrahedral units to produce an excitation state of $\left[\mathrm{Fe}^{2+}-\mathrm{O}^{-}\right]^{*}[9]$ which in turn various forms of active $\mathrm{O}_{2}, \mathrm{O}_{2}^{-}, \cdot \mathrm{OH}, \mathrm{HO}_{2}{ }^{\bullet}$ and $\mathrm{O}^{\bullet}$ produced, may be responsible for the decomposition of organic compound [8]. On the other hand, the enhancement in photoactivity of $\mathrm{TiO}_{2} / \mathrm{Fe}-\mathrm{ZSM}-5$ is due to the Fe-containing ZSM-5 system that act as both electron and hole traps. Furthermore, Fe-containg ZSM-5 shows redox reactions may easily proceed in zeolite without being removed from the framework [29]. Therefore, Fe-containing ZSM-5 framework coated with $\mathrm{TiO}_{2}$ nanoparticles as semiconductor oxides was found to be effective for increasing the photoactivity of $\mathrm{TiO}_{2}$ under under the irradiation of UV light.

Figure 6

\section{Conclusion}

This study showed the kinetics and thermodynamics of the photocatalytic degradation of a real PRWW by a $\mathrm{TiO}_{2} / \mathrm{Fe}-\mathrm{ZSM}-5$ catalyst under UV light. The photocatalytic degradation rate increased with the enhancement of photocatalyst concentration to $3 \mathrm{~g} \cdot \mathrm{l}^{-1}$ but decreased beyond the optimum amount of photocatalyst concentration. $\mathrm{pH}$ value of 4 was found to be favorable for wastewater treatment and degradation rate was much faster at acidic condition compared 
with neutral and basic. The maximum degradation efficiency of the organic pollutants was achieved at a temperature of $45^{\circ} \mathrm{C}$. The degradation rate of organic pollutants followed the first order kinetics. An increase of the temperature facilitates the degradation process and the apparent rate constants follow the Arrhenius relation. The activation energy for photocatalytic degradation of organic pollutants in PRWW was found to be $18.76 \mathrm{~kJ}^{\mathrm{mol}}{ }^{-1}$. Significant reduction in COD values indicates good potential of employing photocatalytic technique using $\mathrm{TiO}_{2} / \mathrm{Fe}-\mathrm{ZSM}-5$ photocatalyst for organic pollutant removal from real PRWWas a treatment system.

\section{Acknowledgement}

This work is financially supported by the Iran National Science Foundation (INSF grant No. 92011962) and Iran Nanotechnology Initiative Council. The authors also wish to thank the Iran nanotechnology initiative council, Tarbiat Modares University (TMU) and the Ministry of Science and Technology for their financial support, Mrs. Haghdoust (Technical assistant in Environmental Laboratory) for her valuable technical assistance in the laboratory.

\section{References}

[1] Diya'uddeen BH. Daud WMAW. Abdul Aziz AR. Treatment technologies for petroleum refinery effluents: A review. Process Safety and Environmental Protection. 2011; 89(2): 95105.

[2] Vaiano V. Sacco O. Stoller M. Chianese A. Ciambelli P. Sannino D. Influence of the Photoreactor Configuration and of Different Light Sources in the Photocatalytic Treatment of Highly Polluted Wastewater. International Journal of Chemical Reactor Engineering, 2014. p. 63.

[3] Miranda-García N. Suárez S. Sánchez B. Coronado JM. Malato S. Maldonado MI. Photocatalytic degradation of emerging contaminants in municipal wastewater treatment plant effluents using immobilized TiO2 in a solar pilot plant. Applied Catalysis B: Environmental. 2011; 103(3-4): 294-301.

[4] Falah HH. Thekra AA. Photocatalytic Treatment of Textile Industrial Wastewater. International Journal of Chemical Sciences. 2010; 8(3): 1353-1364.

[5] Pekakis PA. Xekoukoulotakis NP. Mantzavinos D. Treatment of textile dyehouse wastewater by TiO2 photocatalysis. Water research. 2006; 40(6): 1276-1286.

[6] Linsebigler AL. Lu G. Yates JT. Photocatalysis on TiO2 Surfaces: Principles, Mechanisms, and Selected Results. Chemical Reviews. 1995; 95(3): 735-758. 
[7] Galińska A. Walendziewski J. Photocatalytic Water Splitting over Pt-TiO2 in the Presence of Sacrificial Reagents. Energy and Fuels. 2005; 19(3): 1143-1147.

[8] Yan G. Long J. Wang X. Li Z. Fu X. Photoactive sites in commercial HZSM-5 zeolite with iron impurities: An UV Raman study. Comptes Rendus Chimie. 2008; 11(1-2): 114-119.

[9] Yan G. Wang X. Fu X. Li D. A primary study on the photocatalytic properties of HZSM-5 zeolite. Catalysis Today. 2004; 93-95(0): 851-856.

[10] APHA. Standard Methods for the Examination of Water and Wastewater. Washington, DC: American Public Health Association, 1998.

[11] Soon AN. Hameed BH. Heterogeneous catalytic treatment of synthetic dyes in aqueous media using Fenton and photo-assisted Fenton process. Desalination. 2011; 269(1-3): 1-16.

[12] Jia Z. Miao J. Lu HB. Habibi D. Zhang WC. Zhang LC. Photocatalytic degradation and absorption kinetics of cibacron brilliant yellow 3G-P by nanosized $\mathrm{ZnO}$ catalyst under simulated solar light. Journal of the Taiwan Institute of Chemical Engineers. 2016; 60267-274.

[13] Miao J. Jia Z. Lu H-B. Habibi D. Zhang L-C. Heterogeneous photocatalytic degradation of mordant black 11 with ZnO nanoparticles under UV-Vis light. Journal of the Taiwan Institute of Chemical Engineers. 2014; 45(4): 1636-1641.

[14] Bessa E. Sant'Anna Jr GL. Dezotti M. Photocatalytic/H2O2 treatment of oil field produced waters. Applied Catalysis B: Environmental. 2001; 29(2): 125-134.

[15] Naeem K. Weiqian P. Ouyang F. Thermodynamic parameters of activation for photodegradation of phenolics. Chemical Engineering Journal. 2010; 156(2): 505-509.

[16] Kashif N. Ouyang F. Parameters effect on heterogeneous photocatalysed degradation of phenol in aqueous dispersion of TiO2. Journal of Environmental Sciences. 2009; 21(4): 527533.

[17] Chen S. Liu Y. Study on the photocatalytic degradation of glyphosate by TiO2 photocatalyst. Chemosphere. 2007; 67(5): 1010-1017.

[18] Saien J. Asgari M. Soleymani AR. Taghavinia N. Photocatalytic decomposition of direct red 16 and kinetics analysis in a conic body packed bed reactor with nanostructure titania coated Raschig rings. Chemical Engineering Journal. 2009; 151(1-3): 295-301.

[19] Yatmaz HC. Akyol A. Bayramoglu M. Kinetics of the Photocatalytic Decolorization of an Azo Reactive Dye in Aqueous ZnO Suspensions. Industrial and Engineering Chemistry Research. 2004; 43(19): 6035-6039.

[20] Khodadoust S. Sheini A. Armand N. Photocatalytic degradation of monoethanolamine in wastewater using nanosized TiO2 loaded on clinoptilolite. Spectrochimica Acta Part A: Molecular and Biomolecular Spectroscopy. 2012; 92(0): 91-95.

[21] Evgenidou E. Fytianos K. Poulios I. Photocatalytic oxidation of dimethoate in aqueous solutions. Journal of Photochemistry and Photobiology A: Chemistry. 2005; 175(1): 29-38.

[22] Akpan UG. Hameed BH. Parameters affecting the photocatalytic degradation of dyes using TiO2-based photocatalysts: A review. Journal of Hazardous Materials. 2009; 170(2-3): 520529.

[23] Gupta VK. Jain R. Agarwal S. Nayak A. Shrivastava M. Photodegradation of hazardous dye quinoline yellow catalyzed by TiO2. Journal of Colloid and Interface Science. 2012; 366(1): 135-140.

[24] Saien J. Nejati $\mathrm{H}$. Enhanced photocatalytic degradation of pollutants in petroleum refinery wastewater under mild conditions. Journal of Hazardous Materials. 2007; 148(1-2): 491-495.

[25] Harimurti S. Rahmah AU. Omar AA. Thanapalan M. Kinetics of Methyldiethanolamine Mineralization by Using UV/H2O2 Process. CLEAN - Soil, Air, Water. 2013; 41(12): 1165-1174.

[26] Shahrezaei F. Mansouri Y. Zinatizadeh AAL. Akhbari A. Process modeling and kinetic evaluation of petroleum refinery wastewater treatment in a photocatalytic reactor using TiO2 nanoparticles. Powder Technology. 2012; 221(0): 203-212.

[27] Chowdhury S. Mishra R. Saha P. Kushwaha P. Adsorption thermodynamics, kinetics and isosteric heat of adsorption of malachite green onto chemically modified rice husk. Desalination. 2011; 265(1-3): 159-168. 
[28] Saien J. Shahrezaei F. Organic Pollutants Removal from Petroleum Refinery Wastewater with Nanotitania Photocatalyst and UV Light Emission. International Journal of Photoenergy. 2012; 2012.

[29] Lázár K. Mössbauer spectroscopy in catalysis. Hyperfine Interactions. 2013; 217(1-3): 57-65. 


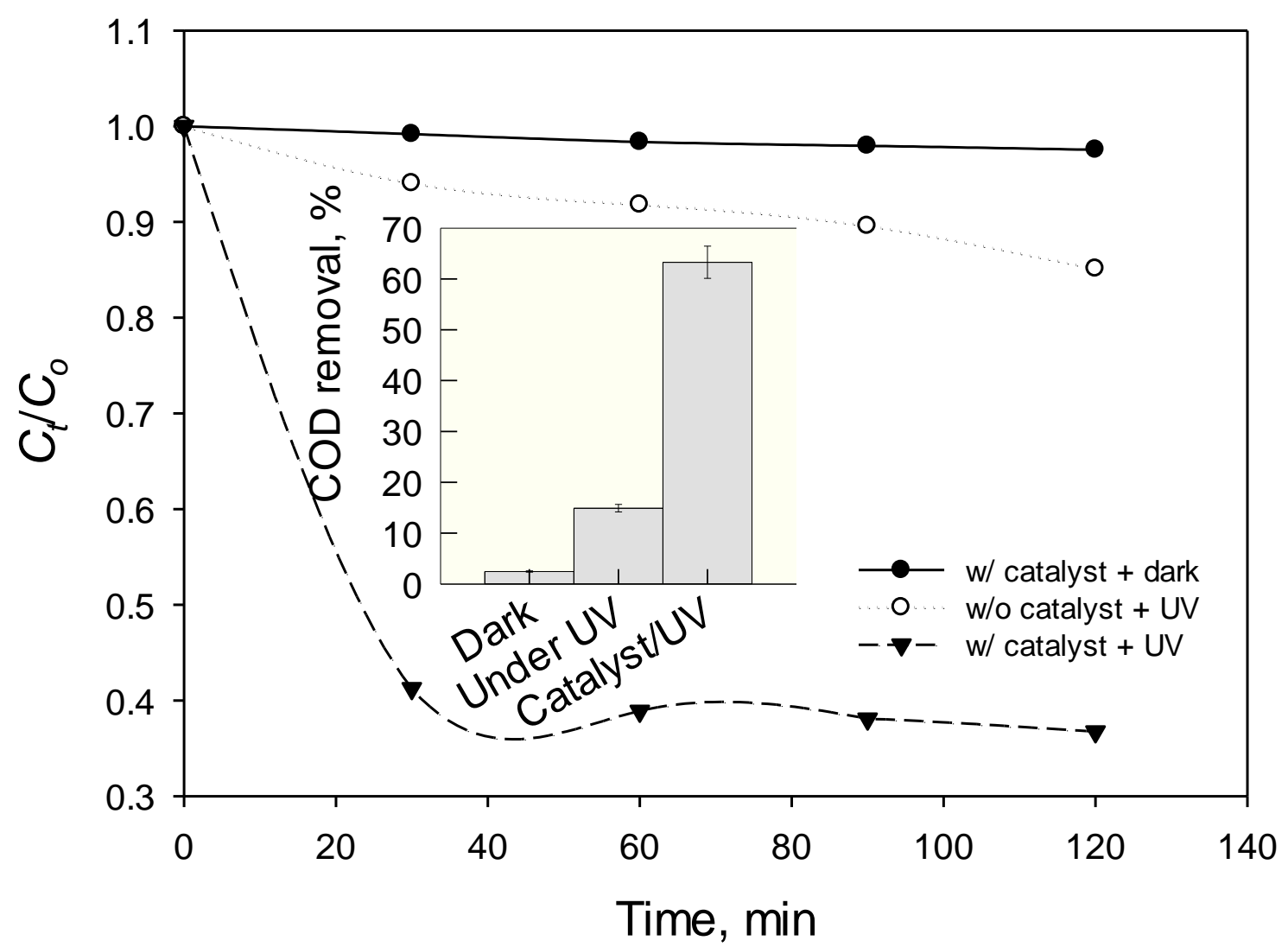

Figure 1. Typical plot of COD removal vs. time in preliminary experiments (a) in the presence of photocatalyst under the absence of UV light (dark condition), (b) in the absence of photocatalyst and under the UV light and (c) in the presence of photocatalyst and under the presence of UV light 


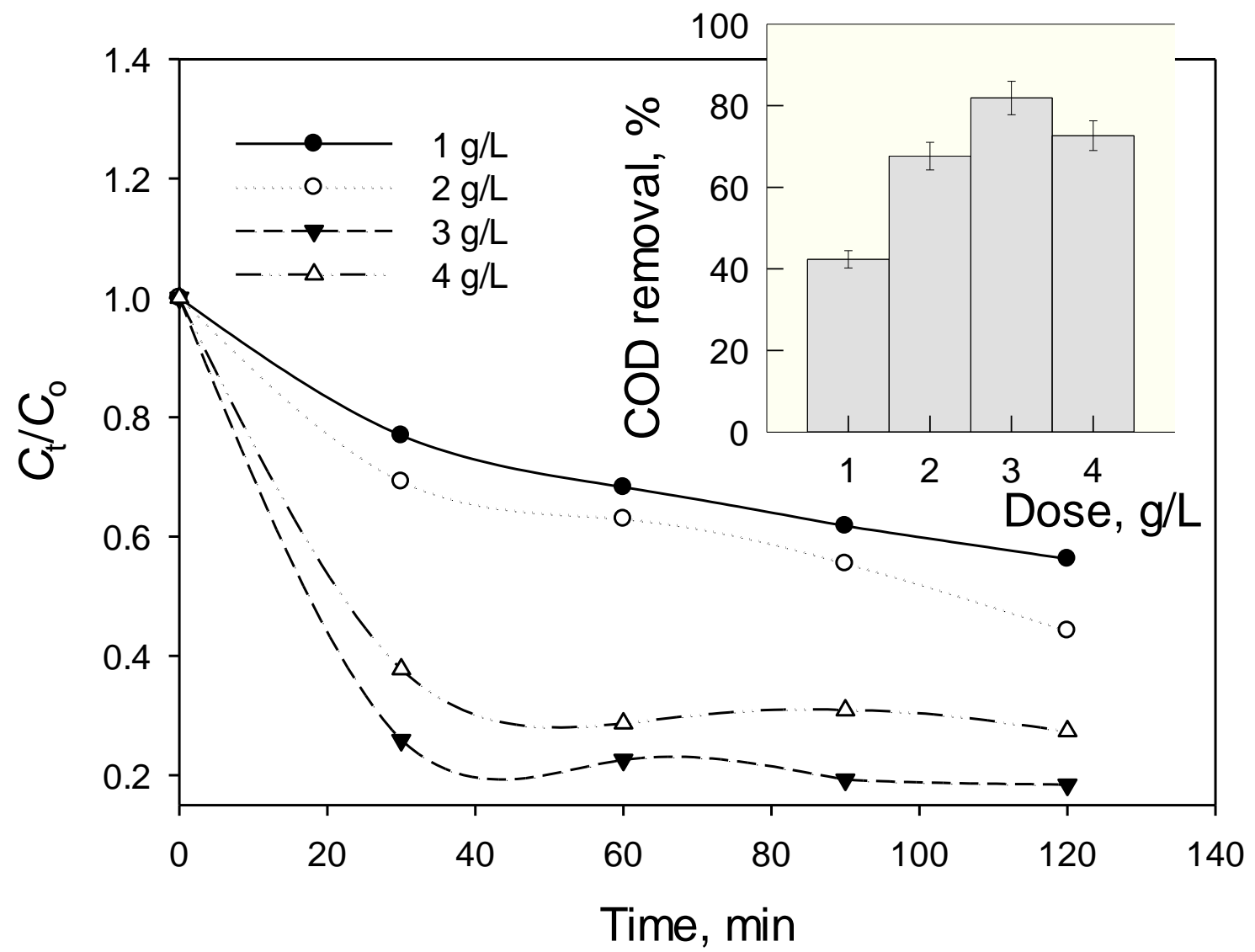

(a)

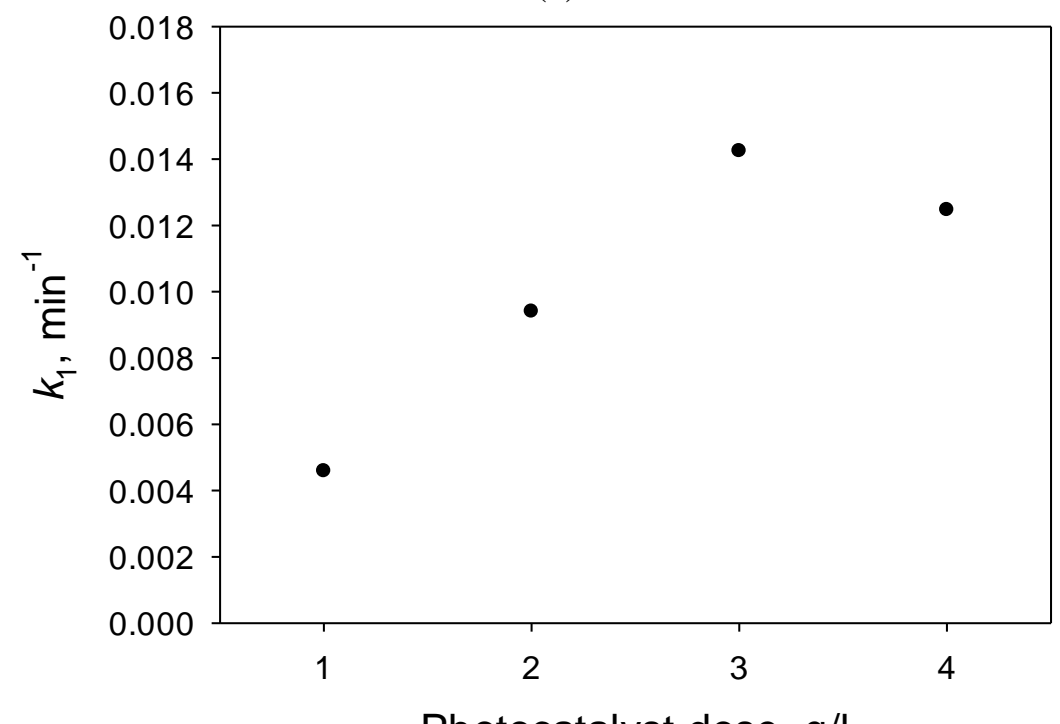

Photocatalyst dose, $\mathrm{g} / \mathrm{l}$

(b)

Figure 2. (a) Effect of photocatalyst concentration on COD removal rate (b) Effect of different amounts of photocatalyst concentration on the kinetic rate constant 

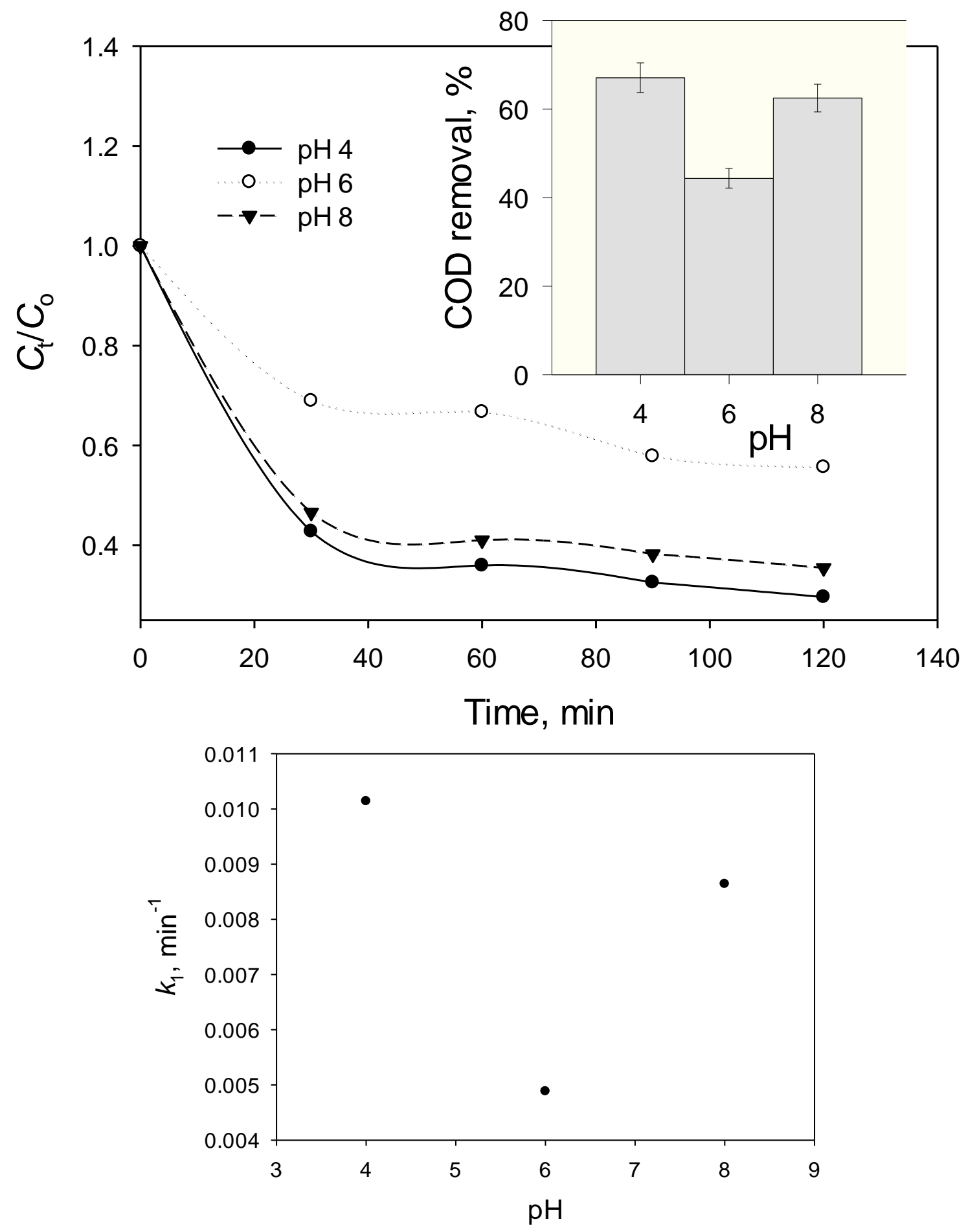

Figure 3. (a) Effect of $\mathrm{pH}$ on COD removal rate (b) photocatalytic rate constant as a function of $\mathrm{pH}$ 


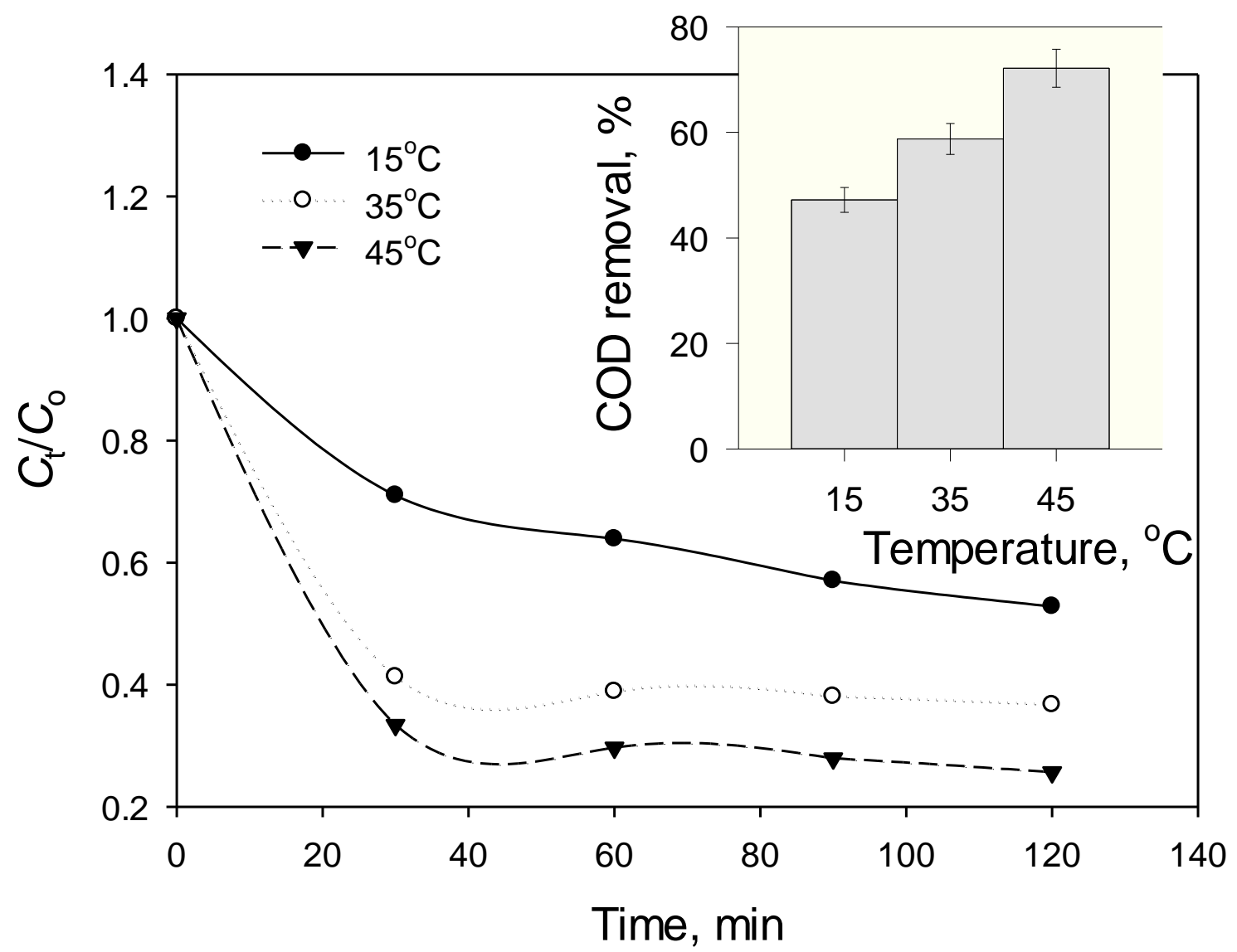

(a)

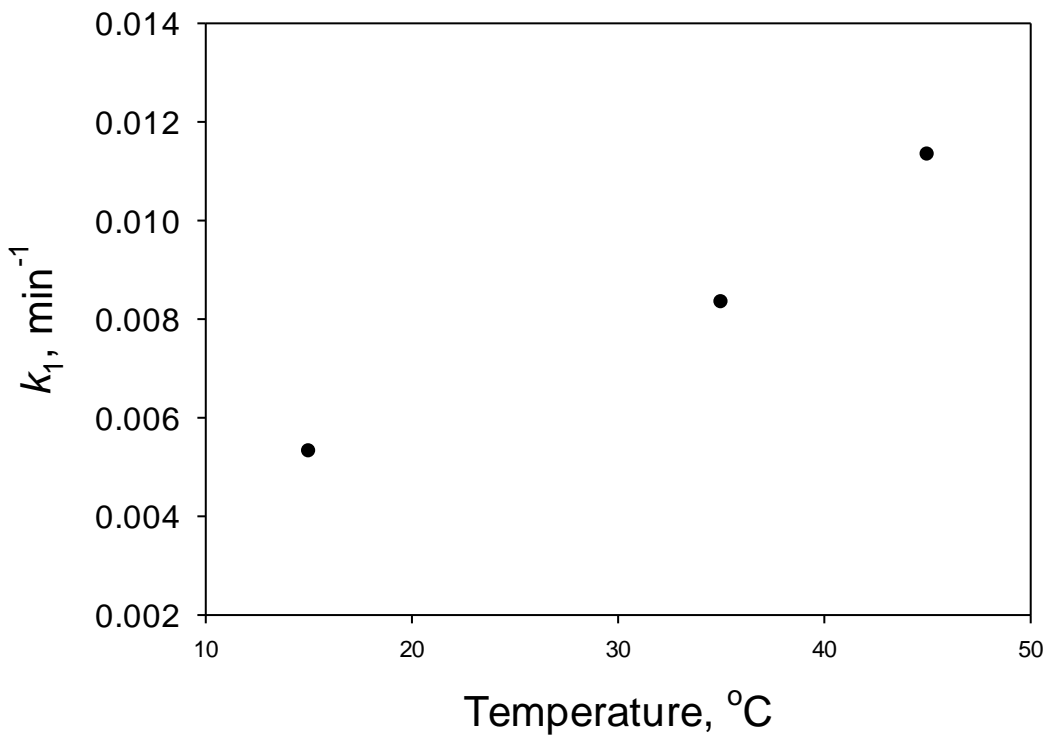

(b)

Figure 4. (a) Effect of temperature on COD removal rate (b) photocatalytic rate constant as a function of temperature 


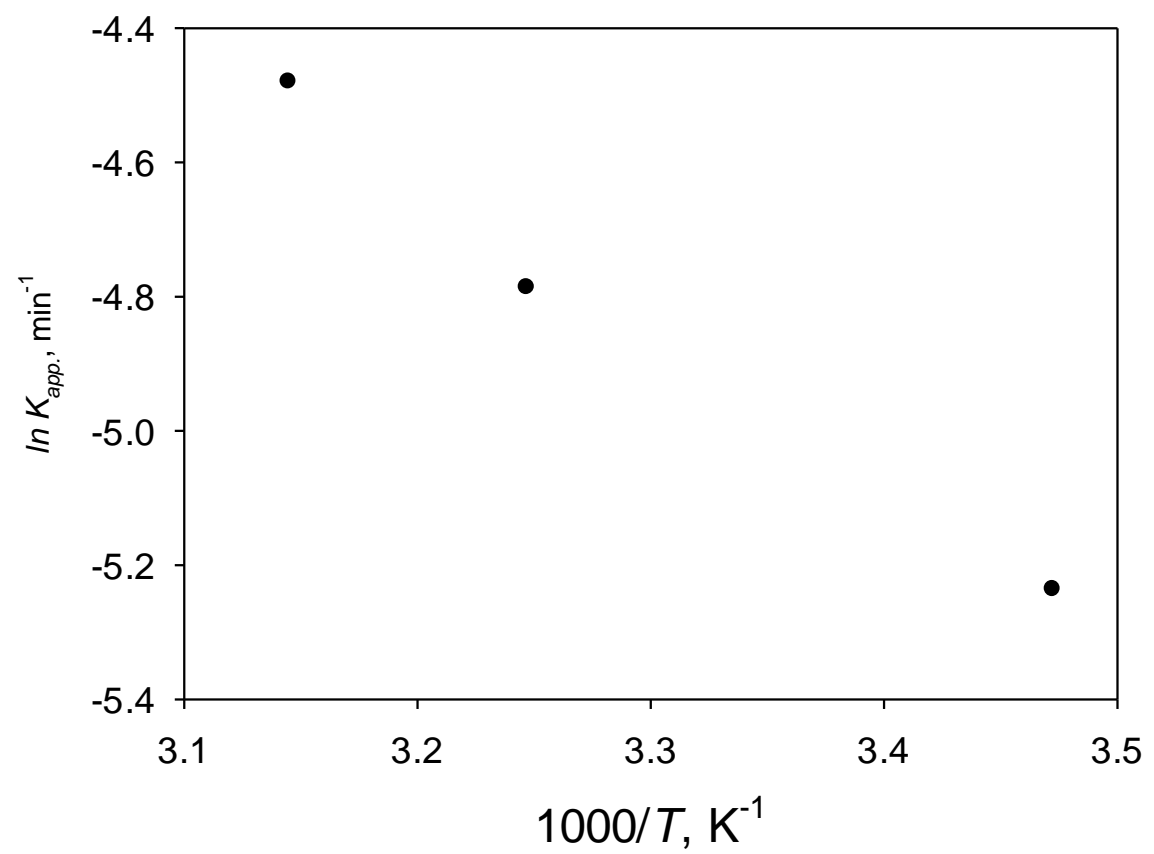

(a)

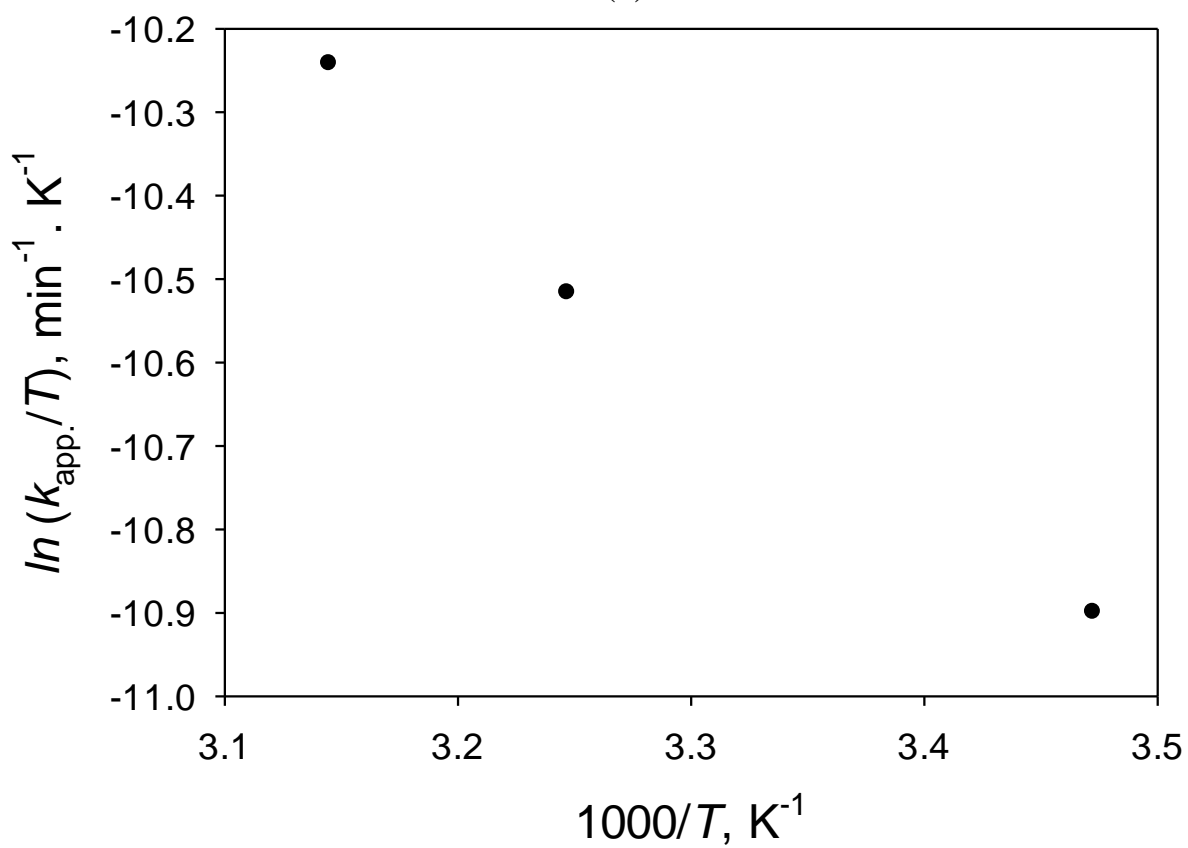

(b)

Figure 5. (a) Arrhenius plot of $\ln k_{\text {app }}$ against reciprocal $\mathrm{T}$ (b) Eyring plot of $\ln \left(k_{\mathrm{app}} / \mathrm{T}\right)$ against reciprocal $\mathrm{T}$ 


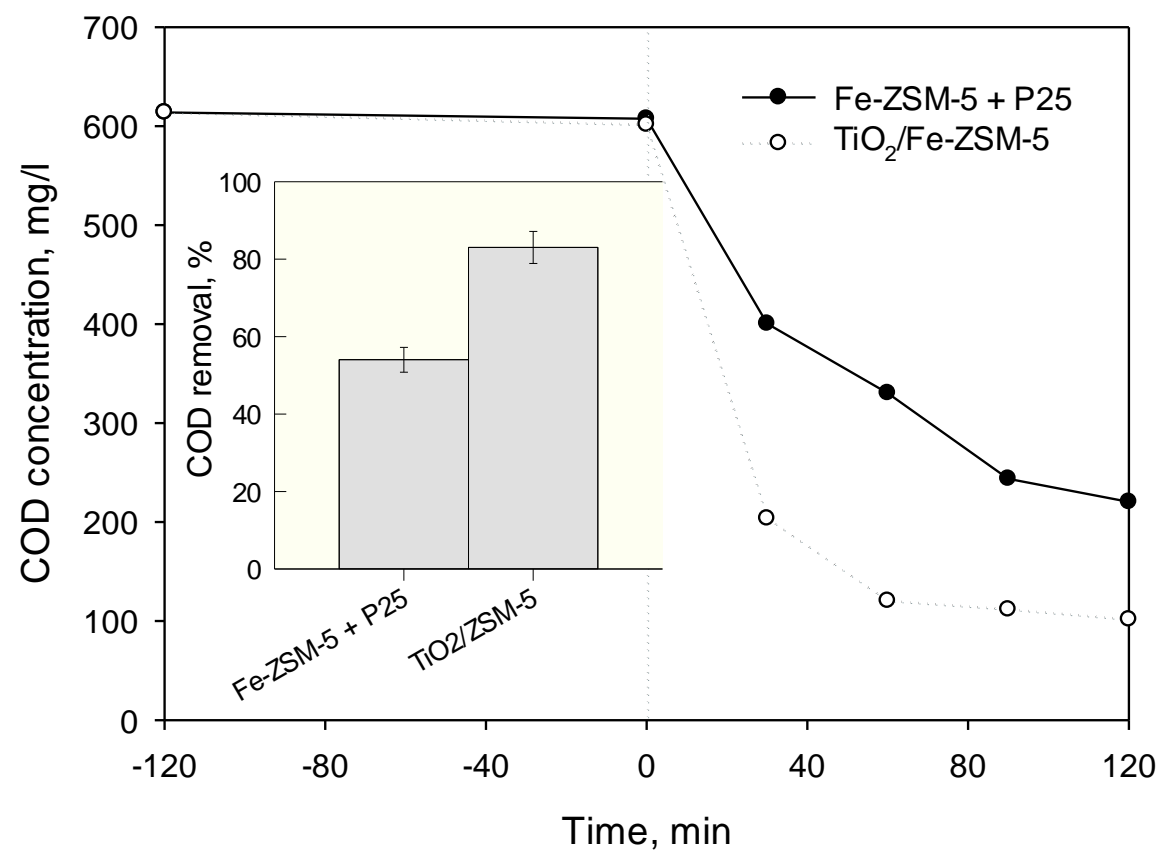

Figure 6. Photocatalytic activity of simple mix of Fe-ZSM-5 and commercial Degussa P25 (2.1 $\mathrm{g} \cdot \mathrm{l}^{-1} \mathrm{Fe}-\mathrm{ZSM}-5$ and $0.9 \mathrm{~s}$ g. $\left.1^{-1} \mathrm{TiO}_{2}\right)$ and synthesized $\mathrm{TiO}_{2} / \mathrm{Fe}-\mathrm{ZSM}-5$ at concentration $3 \mathrm{~g} \cdot \mathrm{l}^{-1}$ at optimal experimental condition: $\mathrm{pH}$ of 4 , photocatalyst concentration of $3 \mathrm{~g} \cdot \mathrm{l}^{-1}$ and temperature of $45^{\circ} \mathrm{C}$ after $120 \mathrm{~min}$ 
Table 1 . The physicochemical parameters of petroleum refinery wastewater

\begin{tabular}{|l|l|l|}
\hline Characteristics & Average & Range \pm SD \\
\hline $\mathrm{pH}^{\mathrm{a}}$ & $7.63-$ & $7.63 \pm 0.5$ \\
\hline Total COD $^{\mathrm{b}}$ & 602 & $602 \pm 30$ \\
\hline Soluble COD $^{\mathrm{b}}$ & 247 & $247 \pm 12.5$ \\
\hline Total BOD (TBOD) $^{\mathrm{b}}$ & 392 & $392 \pm 20$ \\
\hline Total solids (TS) $^{\mathrm{b}}$ & 1725 & $1725 \pm 86.3$ \\
\hline Total dissolved Solids (TDS) $^{\mathrm{b}}$ & 1624 & $1624 \pm 81$ \\
\hline Total suspended solids (TSS) $^{\mathrm{b}}$ & 101 & $101 \pm 5$ \\
\hline Fixed suspended solids (FSS) $^{\mathrm{b}}$ & 79 & $79 \pm 4$ \\
\hline Volatile suspended solids (VSS) $^{\mathrm{b}}$ & 22 & $22 \pm 1.1$ \\
\hline TKN $^{\mathrm{b}}$ & 40.32 & $40.32 \pm 2.02$ \\
\hline EC $^{\mathrm{c}}$ & 1983 & $1983 \pm 100$ \\
\hline DO $^{\mathrm{b}}$ & 4.40 & $4.4 \pm 0.22$ \\
\hline Turbidity $^{\mathrm{d}}$ & 96.36 & $96.36 \pm 4.82$ \\
\hline
\end{tabular}

$\mathrm{a}=$ dimensionless, $\mathrm{b}=\mathrm{mg} / \mathrm{l}, \mathrm{c}=\mu \mathrm{s}, \mathrm{d}=\mathrm{NTU}$ at $25^{\circ} \mathrm{C}$

\begin{tabular}{|c|c|c|c|c|c|c|c|c|c|c|}
\hline \multirow[t]{2}{*}{$\mathrm{T}, \mathrm{K}$} & \multirow{2}{*}{$\begin{array}{l}k_{\text {app, }} \\
\text { min }^{-1}\end{array}$} & \multirow{2}{*}{$\begin{array}{l}\ln \\
\left(k_{\mathrm{app}} / \mathrm{T}\right), \\
\min _{1}^{-1} \cdot \mathrm{K}^{-}\end{array}$} & \multicolumn{3}{|c|}{ Arrhenius theory } & \multicolumn{4}{|c|}{ Transition state theory } & \multirow[b]{2}{*}{$R^{2}$} \\
\hline & & & $\begin{array}{l}E_{a}, \\
\mathrm{~kJ} / \mathrm{mol}\end{array}$ & $\begin{array}{l}A, \\
\min ^{-1}\end{array}$ & $R^{2}$ & $\begin{array}{l}\Delta^{\ddagger} H^{\mathrm{o}}, \\
\mathrm{kJ} / \mathrm{mol}\end{array}$ & $\begin{array}{l}\Delta^{\dagger} S^{\mathrm{o}} \\
\mathrm{kJ} / \mathrm{K} \cdot \mathrm{m} \\
\mathrm{ol}\end{array}$ & $\begin{array}{l}\Delta^{\ddagger} G^{\mathrm{o}} \\
\mathrm{kJ} / \mathrm{m} \\
\mathrm{ol}\end{array}$ & $\begin{array}{l}A, \\
\min ^{-1}\end{array}$ & \\
\hline 288 & $\begin{array}{l}0.00 \\
53\end{array}$ & -10.90 & \multirow[t]{3}{*}{18.77} & \multirow[t]{3}{*}{$\begin{array}{l}13.3 \\
3\end{array}$} & \multirow[t]{3}{*}{$\begin{array}{l}0.989 \\
0\end{array}$} & \multirow[t]{3}{*}{16.26} & \multirow[t]{3}{*}{-0.266} & 92.82 & 4.68 & \multirow[t]{3}{*}{$\begin{array}{l}0.98 \\
58\end{array}$} \\
\hline 308 & $\begin{array}{l}0.00 \\
83\end{array}$ & -10.52 & & & & & & 98.14 & 5.00 & \\
\hline 318 & $\begin{array}{l}0.01 \\
13\end{array}$ & -10.24 & & & & & & $\begin{array}{l}100.8 \\
0\end{array}$ & 5.16 & \\
\hline
\end{tabular}




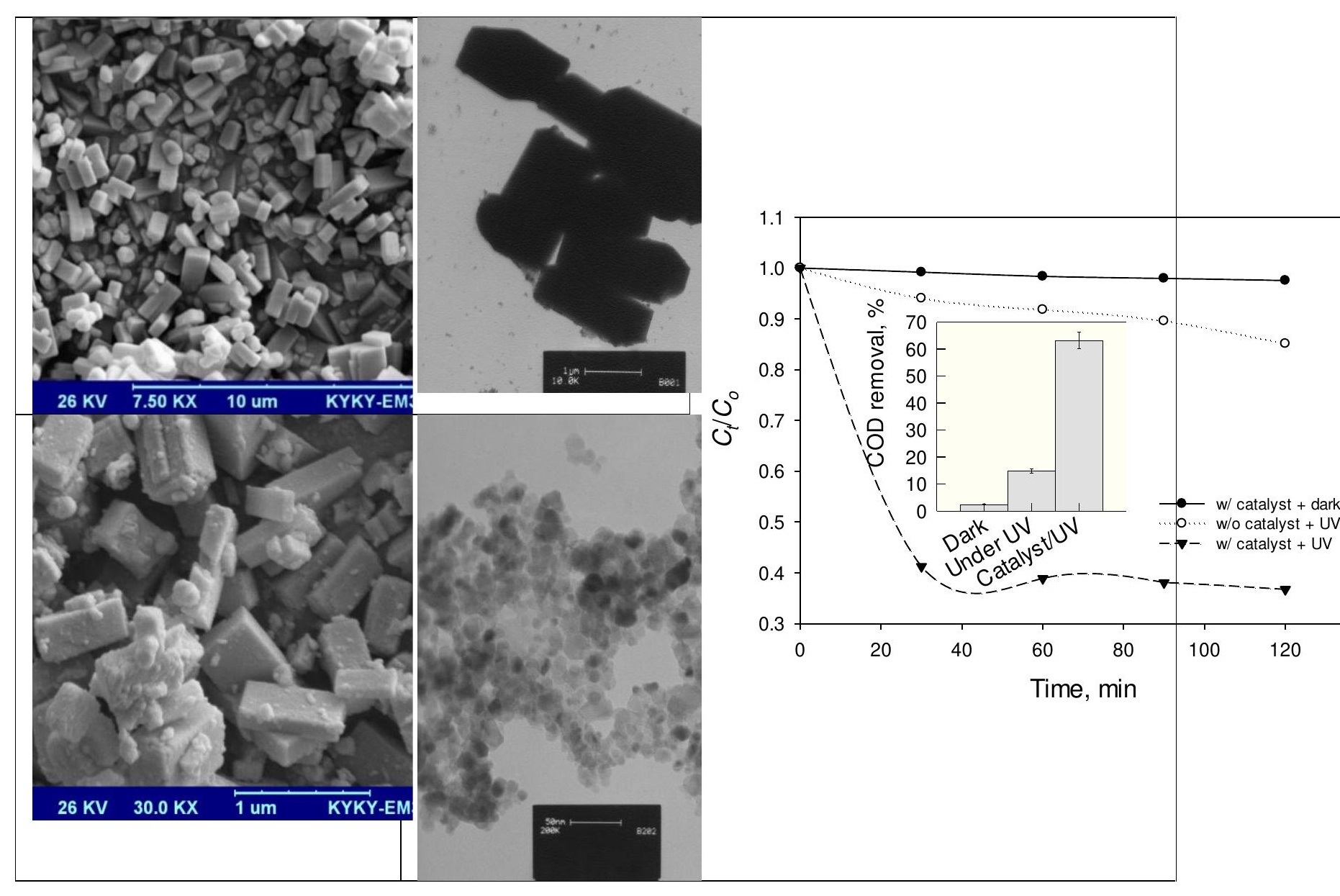

